\title{
From PurUUpurU to Cytokine Storm to Hyperviscosity, Thrombosis and Other Complications of Coronavirus Disease 2019
}

\author{
Gregory Sloop ${ }^{1}$, Brent Ryckman ${ }^{2}$, Gheorghe Pop ${ }^{3}$, Joseph Weidman ${ }^{4}$, and John St. Cyr ${ }^{5}$ \\ ${ }^{1}$ Affiliation not available \\ ${ }^{2}$ University of Montana Missoula \\ ${ }^{3}$ Radboud University Medical Center \\ ${ }^{4}$ none \\ ${ }^{5}$ Jacqmar, Inc.
}

February 19, 2021

\begin{abstract}
Background: Severe coronavirus disease 2019 (COVID-19) is associated with pathological elevations of tumor necrosis factoralpha (TNF-a) and interleukin 6 (IL-6). These cause extreme elevations of the acute phase reactant fibrinogen and plasma viscosity. Severe COVID-19 is also associated with poorly understood complications including a high incidence of arterial and venous thrombosis despite prophylactic anticoagulation, silent hypoxemia, pulmonary microvascular thrombosis, excess neutrophil extracellular trap formation, encephalopathy, and cardiac dysfunction. Aims: To investigate the cause of this pathological inflammatory response, the authors determined the number of purine-uridine-uridine-purine-uridine (purUUpurU) motifs in the genomes of severe acute respiratory syndrome coronavirus 2 (SARS-CoV-2) and other RNA viruses. This motif is the precursor to the oligonucleotide which is the minimal motif required to activate inflammation via toll-like receptor 8 (TLR8). A genome containing the same nucleotides in SARS-CoV-2 in random order was used as a control. Result: PurUUpurU occurred 2.8 times more often in the actual SARS-CoV-2 genome than the randomized genome. The number of purUUpurU motifs correlates with the severity of the acute illnesses caused by the RNA viruses examined, except for influenza A. Conclusion: Hyperactivation of TLR8 mediated inflammation by purUUpurU may cause pathological inflammation in COVID-19. Marked elevations of TNF-a, IL-6, and fibrinogen will cause erythrocyte aggregation and increase blood viscosity. This promotes thrombosis and decreases tissue perfusion. Therapeutic plasmapheresis reduces blood hyperviscosity and should be used in severe COVID-19. To date, use of this therapy has only been reported in COVID-19 associated thrombosis.
\end{abstract}

\section{Hosted file}

pur motifs.docx available at https://authorea.com/users/396732/articles/509828-frompuruupuru-to-cytokine-storm-to-hyperviscosity-thrombosis-and-other-complications-ofcoronavirus-disease-2019

\section{Hosted file}

figure 1.docx available at https://authorea.com/users/396732/articles/509828-from-puruupuruto-cytokine-storm-to-hyperviscosity-thrombosis-and-other-complications-of-coronavirusdisease-2019

\section{Hosted file}

figure 2 covid paper.docx available at https://authorea.com/users/396732/articles/509828from-puruupuru-to-cytokine-storm-to-hyperviscosity-thrombosis-and-other-complicationsof-coronavirus-disease-2019 